\title{
Effects of sample duration, retention interval, and passage of time in the test on pigeons' matching-to-sample performance
}

\author{
VERONIKA T. GUTTENBERGER and EDWARD A. WASSERMAN \\ University of Iowa, lowa City, Iowa
}

\begin{abstract}
Four pigeons served as subjects in an experiment using the go/no-go delayed matching-to-sample paradigm. The go/no-go method was used because it permits the experimenter to track the time course of discriminative performance throughout the test period, unlike the conventional choice matching procedure. It was found that discriminative test performance increased with longer sample durations; performance decreased with longer retention intervals and also as time passed in the test period. The rate of forgetting was virtually the same when either the retention interval was lengthened or time elapsed in the test. These findings support a modified trace theory, which proposes that the sample stimulus trace decays at a constant rate from the point of sample offset, and that the decaying memory trace is repeatedly compared with the prevailing test stimulus as time passes in the test period.
\end{abstract}

The delayed matching-to-sample (DMTS) procedure has been used extensively to study animal short-term memory. In this conditional discrimination procedure, a sample stimulus is presented for a specified period of time, after which a delay or retention interval is imposed, followed by presentation of one or more test stimuli. In the choice DMTS procedure, two or more test stimuli are presented and the subject must select the stimulus that matches the prior sample in order to earn reinforcement (Blough, 1959). Another kind of DMTS procedure involves presentation of only one test stimulus at a time. If the test stimulus matches the prior sample, reinforcement is scheduled; however, if the test stimulus does not match the sample, no reinforcement is delivered. The subject's "choice" here is whether or not to respond (Konorski, 1959; Wasserman, 1976). This second method can be called go/no-go DMTS.

In the typical choice DMTS procedure, the test stimuli offset as soon as a response is made, whereas in the go/no-go task, the test stimulus may remain on for longer periods of time. Having the test stimulus stay on beyond the first response permits an evaluation of subjects' response rates. Wasserman (1976), for example, found that pigeons responded differentially on matching and nonmatching trials, with overall response rates higher on matching trials. The mean latencies to the first test key-

This research is based on the first author's thesis, submitted to the University of Iowa in partial fulfillment of the requirements for the MA degree. The authors wish to thank Dan Neunaber, Gary Schroeder, and Diane Chatlosh for their help with this project. The comments of the Editor and two anonymous reviewers were also of considerable value to the preparation of this report. Requests for reprints should be sent to E. A. Wasserman, Department of Psychology, University of Iowa, Iowa City, IA 52242. peck were longer on nonmatching than on matching trials. Furthermore, after latency times were subtracted, the mean running rates showed that differential responding still occurred on matching and nonmatching trials. That experiment involved a retention interval of $1 \mathrm{sec}$, but later studies, also using the go/no-go DMTS procedure, revealed that longer retention intervals can disrupt discriminative performance (Nelson \& Wasserman, 1978).

More recently, Roitblat (1980) and Wilkie and Spetch (1981) have conducted experiments in which the choice procedure was modified to allow an examination of behavior after initial choices. The results of these two studies also suggest that information about the sample may be available beyond the first test response.

A prime account of animals' behavior under DMTS procedures is trace theory (see, e.g., Roberts \& Grant, 1976). According to trace theory, discriminative performance in DMTS results from the subject's comparing the prevailing test stimulus (or stimuli) with an internal trace of the sample stimulus. Accurate performance results when differential responding is occasioned by test stimuli that do or do not match the prior sample stimulus.

Critical to discriminative performance is the strength of the presumed memory trace; the stronger the trace, the more accurate will be test performance. Trace strength is hypothesized to be a positive function of sample presentation time and a negative function of time since sample offset. Much evidence exists that is consistent with trace theory (Roberts \& Grant, 1976), although data that question the completeness of the account are accumulating (e.g., Grant, 1981; Honig \& Wasserman, 1981).

As originally conceived, trace theory sought to account for the subjects' first response after onset of the test. Thus, only a single comparison of the memory trace with the test stimulus (or stimuli) was deemed necessary to guide 
accurate test behavior. However, given that discriminative performance can be observed after the first test response (Roitblat, 1980; Wasserman, 1976; Wilkie \& Spetch, 1981), it becomes evident that trace theory must be modified to allow the possibility of multiple trace-test comparisons. Accordingly, so long as the test continues, subjects may repeatedly compare their memory of the prior sample stimulus with the prevailing test stimulus (or stimuli).

A clear implication of this multiple comparison version of trace theory is that discriminative performance ought to decline as time passes during the test. The logic here is that as time elapses during the test, the interval since sample-stimulus offset increases. And the longer the time since offset of the sample stimulus, the weaker should be its internal memory trace.

If one makes the simplest assumption that the passage of time since sample offset is the sole determinant of memory trace decay, a further implication follows from the fact that either of two independent parameters-the sample-offset-test-onset period and the duration of test presentation-increases this interval: No matter how the time since sample offset is lengthened, such increases should have identical detrimental effects on discriminative test performance. Thus, lengthening the time since sample offset by $\mathrm{t} \mathrm{sec}$-whether by increasing the sampleoffset-test-onset interval or by equivalently increasing the duration of the test stimulus-should equally decrease test performance.

The present experiment was designed to determine how, if at all, pigeon memory changes throughout the duration of the test stimulus and to compare this effect with that of lengthening the sample-test retention interval. By carefully tracking responding during the test phase in the go/no-go DMTS task, assessments can be made of the retention interval and the test interval as these independently and mutually affect discriminative performance.

Until now, the pattern of discrimination changes occurring in the test phase of a trial has not been of primary interest. In the Nelson and Wasserman (1978) study, for example, test intervals were not divided into subsections, allowing only an overall computation of discriminative performance; in addition, all test intervals were of a fixed, short duration $(5 \mathrm{sec})$. For the present study, test intervals were subdivided, so that the time course of discriminative responding could be recorded in up to six successive 2 -sec segments. Test stimuli of variable duration were used within each session to reduce the scalloping typical of responding on fixed-interval schedules (Ferster \& Skinner, 1957).

In addition, the present experiment was carried out to study the effect of samples presented for different durations. Sample duration has been shown to affect discriminative test performance in both choice and go/no-go DMTS procedures (e.g., Nelson \& Wasserman, 1978; Roberts \& Grant, 1976). Generally, performance tends to improve with longer sample durations. The negatively accelerated form of these functions suggests that trace growth is exponential. Furthermore, assuming exponential decay, trace theory (Roberts \& Grant, 1976) predicts that the performance functions of different sample durations ought to be negatively decelerated and convergent. Although Nelson and Wasserman (1978) obtained this result using the go/no-go task, the outcome of studies carried out by Roberts (1972) and Grant (1976), using the more typical choice procedure, did not suggest a convergence of decay functions. It was therefore of interest in this experiment to see how variations in sample length would affect discriminative responding throughout test presentation and at different retention intervals.

\section{Subjects}

\section{Method}

Four experimentally naive adult feral pigeons, reduced to $85 \%$ of their free-feeding weights, were used as subjects. The birds were individually housed, with water and grit always available. Supplemental mixed grain was given in home cages after sessions, wher required. A dose of poultry vitamins, dissolved in the water, was given every 3 days. The home cages were in a $24-\mathrm{h}$-lit colony room.

\section{Apparatus}

Four identical three-key pigeon chambers, measuring $31.5 \times 30.5 \times 36 \mathrm{~cm}$, were used with the two side keys inoperative. The center response key was $2 \mathrm{~cm}$ in diameter and required a forct of $.05 \mathrm{~N}$ for activation; it could be transilluminated with orange or green light through the use of a miniature display projector (IEE Series 10, CM 44 lamps, $5.5 \mathrm{~V} \mathrm{dc}$ ) mounted behind the cleal Plexiglas key. The top of the response key measured $4.9 \mathrm{~cm}$ front the bottom of the houselight (CM 44 lamp, $5.5 \mathrm{~V} \mathrm{dc}$ ), which was encased in a black metal housing that directed the light toward the ceiling. The bottom of the response key was $9.3 \mathrm{~cm}$ above the top of the solenoid-operated grain hopper (BRS/LVE 114-10), which had an opening of $5.8 \times 5.2 \mathrm{~cm}$. During reinforcement, hopper il + lumination was provided by an ESB 24 bulb at $24 \mathrm{~V} \mathrm{dc}$. All chamber walls were of aluminum. An elevated grid covered the floot of each chamber. Chamber ventilation and white noise were continually provided. In a separate room, a DEC PDP-8/A minicomputer controlled experimental events and data collection with the SKED software system (Snapper, Stephens, \& Lee, 1974).

\section{Procedure}

Preliminary training. The birds were first trained to eat from the food hopper. Following 3 days of feeder training, the birds wer autoshaped to peck the center key when it was lit either orange of green. Each autoshaping session contained 48 trials, with the twd colors occurring 24 times each. The colors appeared randomly, six times each in the first 12 trials, and this was repeated in successive fourths of each session, with each fourth having a different ran. dom sequence. Autoshaping lasted 8 days, at which point all birds were responding reliably to each key-light stimulus.

DMTS acquisition. The birds were next put on DMTS acquisi tion. A variable intertrial interval separated trials by 10,15 , of $20 \mathrm{sec}$, the values chosen at random and with equal probability A response occurring before the intertrial interval had timed ou1 caused the interval value to reset, thus delaying sample onset. The purpose of this contingency was to discourage responding betweer trials. When the intertrial interval had timed out, the sample stimulus (either orange or green light) came on. The first peck to the sam. ple after $8 \mathrm{sec}$ had elapsed terminated the sample and initiated the retention interval. Keypecks made during retention intervals hac no programmed consequences. After this delay had timed out, the test stimulus (either orange or green light) was presented. Reten. tion intervals and test stimulus durations were 2,6 , or $10 \mathrm{sec}$ and 4,8 , or $12 \mathrm{sec}$, respectively. In order to terminate the test stimulus 
and to receive reinforcement on matching trials (orange-orange and green-green), a keypeck was required after the test stimulus duration had elapsed. On nonmatching trials (orange-green and greenorange), the test stimulus terminated automatically after the selected duration had elapsed and led to blackout. All hopper durations and blackouts were $2 \mathrm{sec}$ long, during which time the otherwise illuminated houselight was turned off. All sessions ended with an intertrial interval.

Four possible stimulus combinations, three retention intervals, and three test durations resulted in 36 different trial types. Parameters were chosen for each trial in such a way that each of the 36 trial types occurred randomly without replacement in successive thirds of each session, for a total of 108 trials per session. Training lasted 90 days.

Experimental phase. All of the procedural details were identical to the acquisition phase, except that sample durations were varied between sessions. Samples were presented for $2,4,8$, or $16 \mathrm{sec}$ in a random-block design; each of the four values was imposed once in each of the 10 4-day blocks. The experimental phase began immediately after the acquisition phase and lasted 40 days.

\section{Dependent Variables}

The mean response rates on matching and nonmatching trials were calculated for the 12-sec tests at each retention interval. Only the 12 -sec tests were used, because these durations necessarily comprise the two shorter test durations. Responses made during these tests fell into six consecutive 2 -sec bins. Discrimination ratios (DRs) were computed in each bin from the rates of response on matching and nonmatching trials by the following equation: $\mathrm{DR}=$ (rate of response on matching trials)/(rate of response on matching trials + rate of response on nonmatching trials) $\times 100$. A DR of 50 indicates indiscriminate performance; the DR approaches 100 as performance improves. The DR metric was chosen to describe these data for the following reasons: (1) It combines two scores of interest into one, thus facilitating data inspection and comparison, and (2) as a relative measure, it does not reflect the wide response rate variability existing among subjects.

\section{RESULTS}

Visual inspection of the data revealed that response rates were much lower during the first $2 \mathrm{sec}$ of the 12 -sec matching tests than during the remaining $10 \mathrm{sec}$. Results obtained by Wasserman (1976) showed that the mean latency to the first response on matching trials at a $1-\mathrm{sec}$ retention interval was about $0.8 \mathrm{sec}$. No doubt, this latency reflects the time taken by the birds to orient toward, approach, and contact the response key after illumination. It was therefore decided to omit the first of the six $2-\mathrm{sec}$ bins from all analysis reported here (the data from all six bins are presented in Guttenberger, 1983).

\section{DMTS Acquisition}

A test time (five 2 -sec bins) $\times$ retention interval (three values) $\times$ blocks (nine 10-day blocks) $\times$ subjects (four pigeons) ANOVA was carried out on the DR data. The main effects of blocks, retention interval, and test time were all significant $[\mathrm{F}(8,24)=6.48, \mathrm{p}<.001 ; \mathrm{F}(2,6)$ $=20.02, \mathrm{p}<.01 ; \mathrm{F}(4,12)=38.03, \mathrm{p}<.001$, respectively]. Overall discrimination performance improved over the 90 daily sessions of acquisition; performance decreased as the length of the retention interval increased; and performance declined as a function of time in the test period. A fuller presentation of these data is contained in Guttenberger (1983).

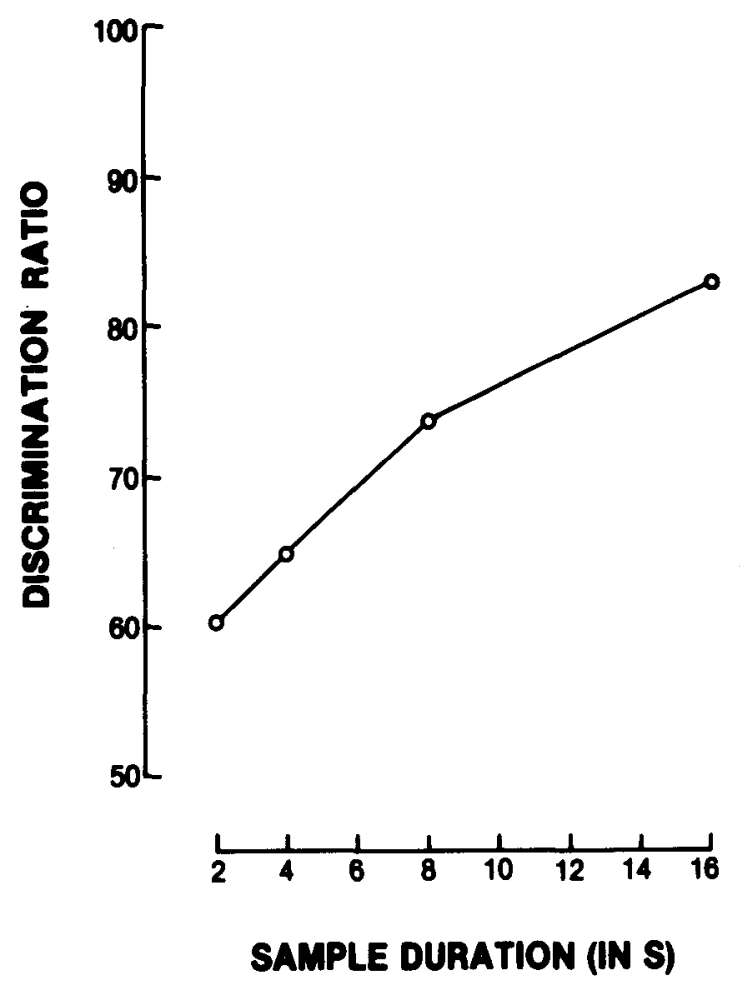

Figure 1. Mean discrimination ratios at different sample durations $(2,4,8$, and $16 \mathrm{sec})$.

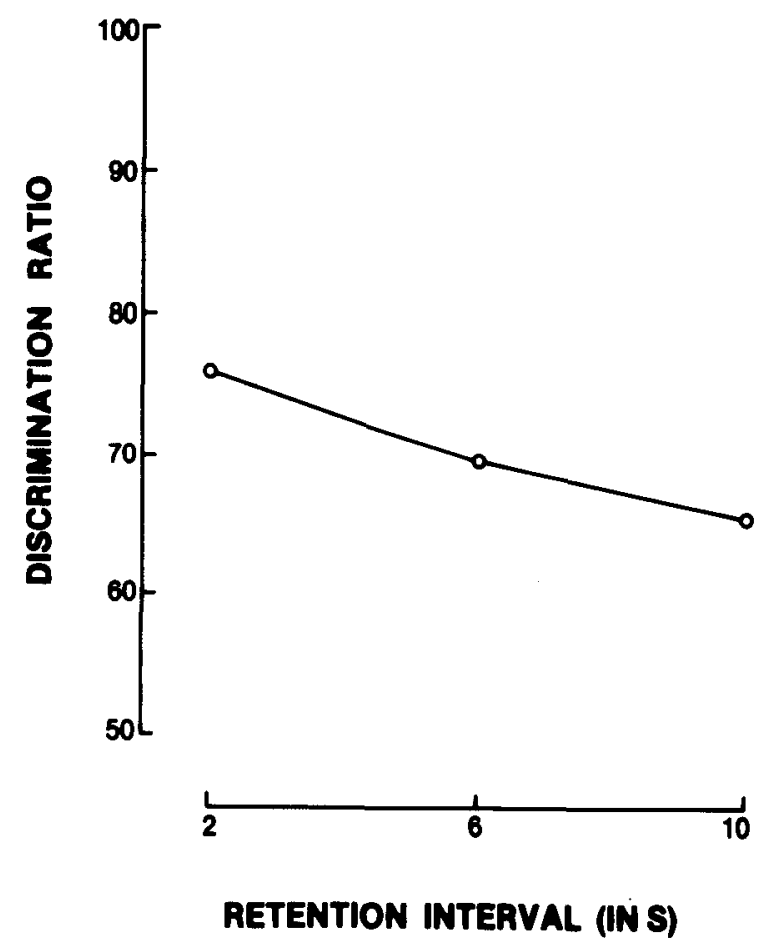

Figure 2. Mean discrimination ratios at different retention intervals $(2,5$, and $10 \mathrm{sec})$.

\section{Experimental Phase DR.}

The curve plotting DR against sample duration is presented in Figure 1. Performance improved, although diminishingly so, as sample duration increased. Figure 2 
shows DR as a function of retention interval. Performance decreased linearly as retention interval increased. DR, as a function of the passage of time in the test stimulus, is shown in Figure 3. Performance declined linearly as time in the test progressed. (It should be noted that the abscissa units denote the midpoints of the 2-sec test bins on this and all other figures and tables in which functions are plotted against the passage of time in the test or the time since sample offset.)

A sample duration $\times$ retention interval $\times$ test time $\times$ subjects ANOVA was carried out on the DR data. The main effects of sample duration, retention interval, and test time were all significant $[F(3,9)=162.51, \mathrm{p}<.001$; $\mathrm{F}(2,6)=11.32, \mathrm{p}<.01 ; \mathrm{F}(4,12)=23.18, \mathrm{p}<.001$, respectively]. Only one interaction, test time $\times$ retention interval, was significant $[\mathrm{F}(8,24)=3.46, \mathrm{p}<.01]$. Figure 4 reveals that the three retention-interval functions tended to converge slightly over time in the test, with the curve for the shortest retention interval declining the fastest.

\section{Time Since Sample Offset}

From the point of view of trace theory, the discrimination data can be further analyzed in terms of the time since sample offset. If the sample trace begins a decay process immediately upon sample offset, then this decay should be apparent throughout the course of the test period. In addition, the level of decay ought to reflect the duration of the retention interval in such a way that, in the initial part of the test phase, shorter retention intervals give rise to higher DRs than do longer retention intervals. And,

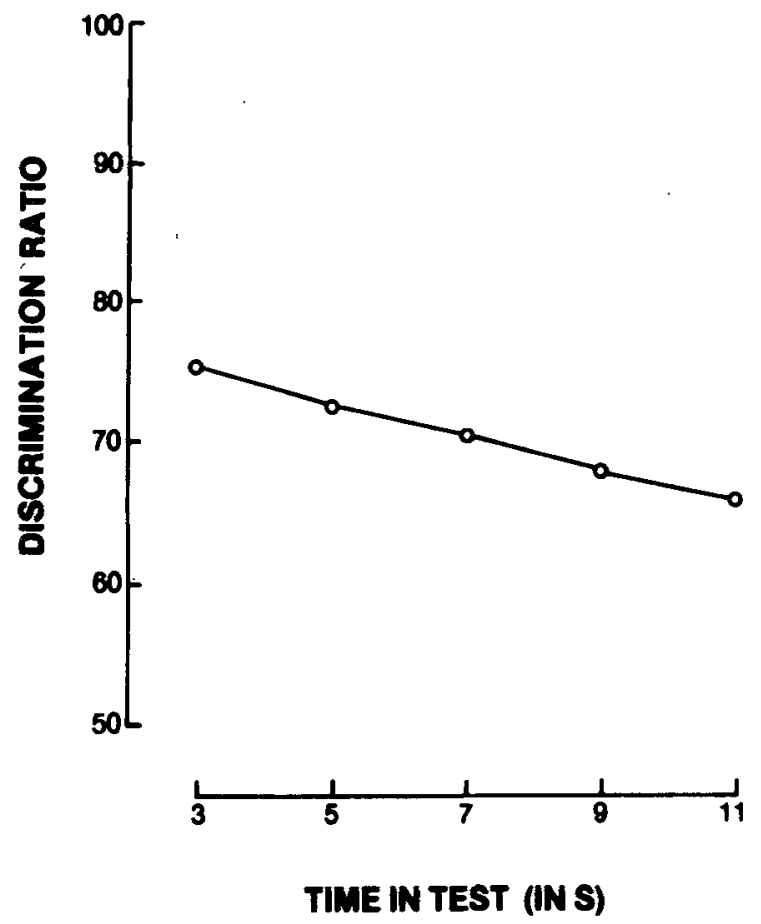

Figure 3. Mean discrimination ratios throughout time in the test $(3,5,7,9$, and $11 \mathrm{sec})$. if the trace decays at the same rate during the retentio interval as it does during the test period, then all of thi data plotted in Figures 1 through 4 should be fit by thi same decay curve.

The mean DRs obtained for each sample duration $(2,4$ 8 , and $16 \mathrm{sec})$, at each retention interval $(2,6$, and $10 \mathrm{sec})$ and for each of the five test bins (the first 2-sec bin having been omitted) were first plotted separately to yield the fou functions in Figure 5, one for each sample duration. Here the abscissa is time since sample offset. For each samply duration, discriminative performance fell as the time sinct sample offset increased. And for each sample duration the data points appeared to be nicely fit by a generally linear decreasing function.

Visual scrutiny revealed that the highest point on thy 8-, 4- and 2-sec functions (i.e., the first bin for the 2-sed retention interval in each case) had a DR virtually identi cal to that of the fourth point on the function for the nex longer sample duration. This fact suggested that these fou individual functions could be accounted for by a singl underlying function. Such an outcome would be consis tent with the notion that the memory trace grows to highe: initial values as the sample duration is increased, and tha the trace decays at the same rate from each of these dif ferent initial values.

It was therefore decided to combine these four func tions in the following way: The complete set of point: obtained under the 8-sec sample duration was shifted alon! the abscissa to the place where the highest point for thi: sample duration met its match on the set of points belong ing to the 16-sec sample duration (which was not shifted)

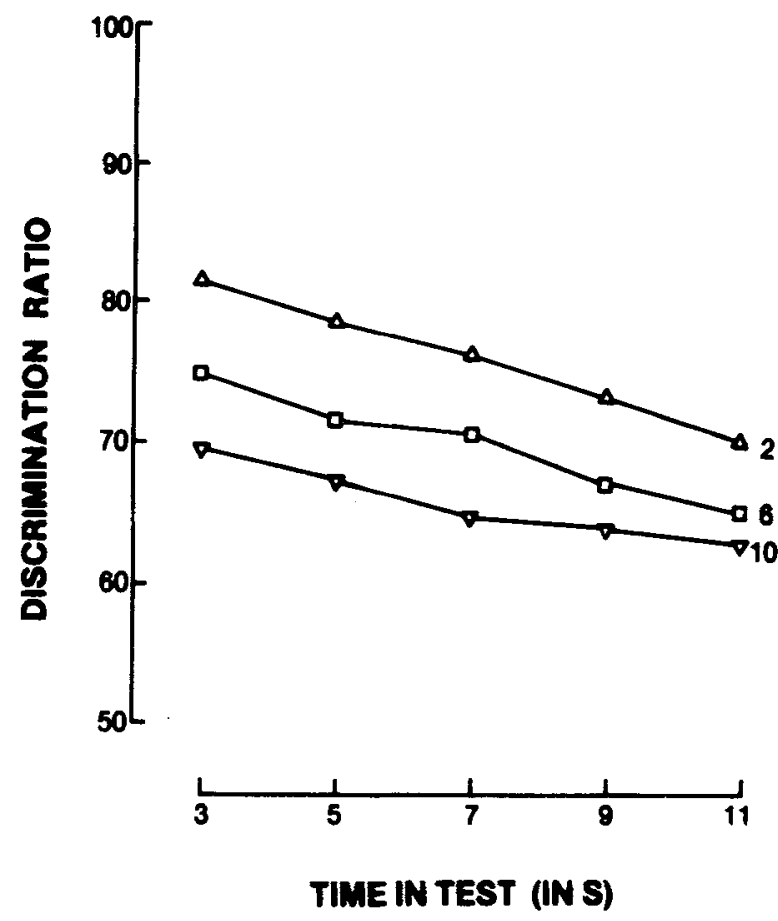

Figure 4. Mean discrimination ratios throughout time in the tes with retention interval (RI) as the parameter. 


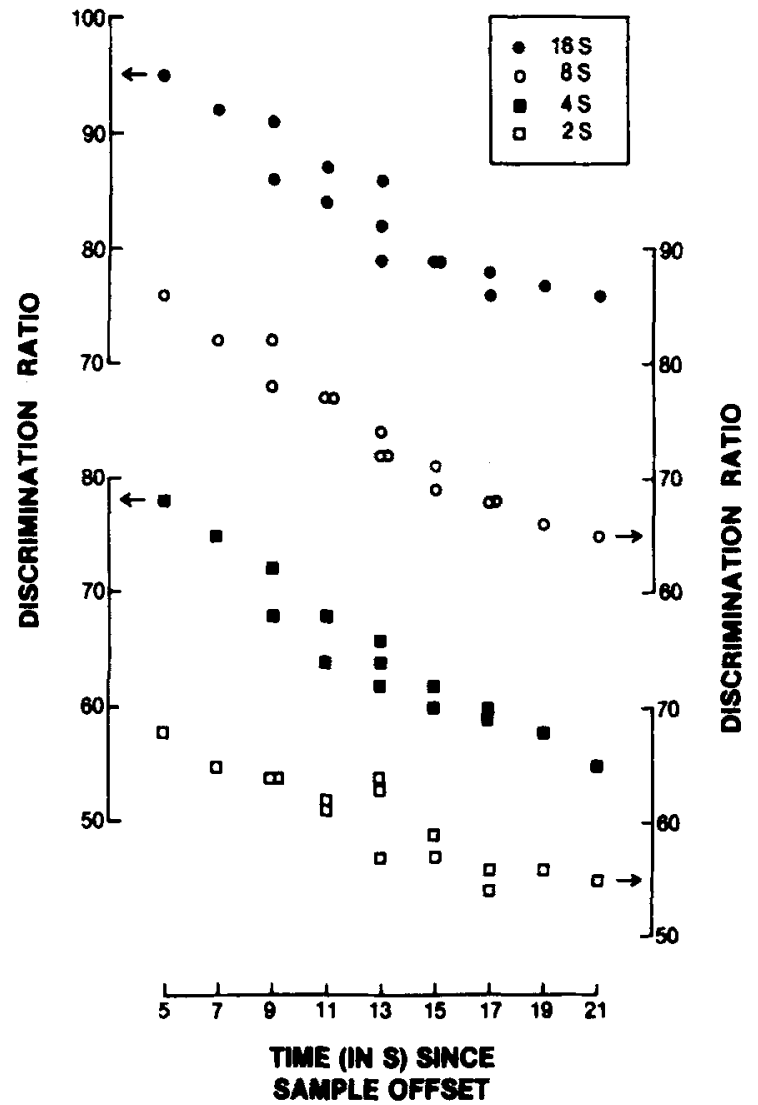

Figure 5. Mean discrimination ratios over time since sample offset for each sample duration.

The set of 4-sec sample duration points was shifted to where the highest point here matched its equal on the shifted set of 8-sec sample duration points, and so on. Figure 6 displays the result of this replotting. The plotted points range from slightly above a level of 50 to a near perfect discrimination of 100 . They decrease in a slightly exponential manner as the time since sample offset increases from 5 to $39 \mathrm{sec}$. Nonetheless, a simple linear equation accounted for $94.64 \%$ of the variance for the points in Figure 6.

\section{Response Rate}

In prior reports using the go/no-go DMTS procedure, memory effects were most consistently the consequence of changes in test responding on nonmatching trials; changes in test responding on matching trials affected memory performance less consistently (e.g., Nelson \& Wasserman, 1978). The same is true of the present study.

Table 1 shows mean test response rates on matching and nonmatching trials as functions of sample duration, retention interval, and time in the test. Overall, mean test response rates were higher on matching trials ( 1.99 pecks/ sec) than on nonmatching trials $(1.00 \mathrm{pecks} / \mathrm{sec})$; this difference was statistically significantly $[F(1,3)=25.07$, $\mathrm{p}<.05]$.

When sample duration was increased, response rate was differently affected on matching and nonmatching trials
$[\mathrm{F}(3,9)=16.45, \mathrm{p}<.01]$. Mean test response rate decreased reliably on nonmatching trials $(1.43,1.23, .84$, $.50 \mathrm{pecks} / \mathrm{sec})$ as sample duration was increased from 2 to 4 to 8 to $16 \sec [F(3,9)=14.73, p<.01]$, but did not reliably change on matching trials $(1.97,1.98,2.01$, $2.02 \mathrm{pecks} / \mathrm{sec}$ ).

When the retention interval was increased, response rate was differently affected on matching and nonmatching trials $[\mathrm{F}(2,6)=10.10, \mathrm{p}<.05]$. Mean test response rate increased reliably on nonmatching trials $(.79,1.01$, $1.21 \mathrm{pecks} / \mathrm{sec}$ ) as the retention interval was increased from 2 to 6 to $10 \mathrm{sec}[\mathrm{F}(2,6)=6.17, \mathrm{p}<.05]$, but it decreased reliably on matching trials $(2.03,1.99$, 1.95 pecks $/ \mathrm{sec})[\mathrm{F}(2,6)=7.38, \mathrm{p}<.05]$.

Finally, when the passage of time in the test increased from 3 to 5 to 7 to 9 to $11 \mathrm{sec}$, response rate rose reliably on both nonmatching trials $(.71, .90,1.01,1.14$, 1.25 pecks $/ \mathrm{sec})[\mathrm{F}(4,12)=15.61, \mathrm{p}<.001]$ and matching trials $(1.77,1.98,2.02,2.09,2.11$ pecks $/ \mathrm{sec})[\mathrm{F}(4,12)$ $=3.34, \mathrm{p}<.05]$. However, the increase in test response rate on nonmatching trials was reliably greater than that on matching trials $\mathrm{F}[(4,12)=4.38, \mathrm{p}<.05]$.

\section{DISCUSSION}

Some of the results of the present study replicate earlier published findings. First, DMTS performance rose with increases in the duration of the sample stimulus (Grant, 1976; Nelson \& Wasserman, 1978; Roberts, 1972). Second, DMTS performance fell with increases in the sample-

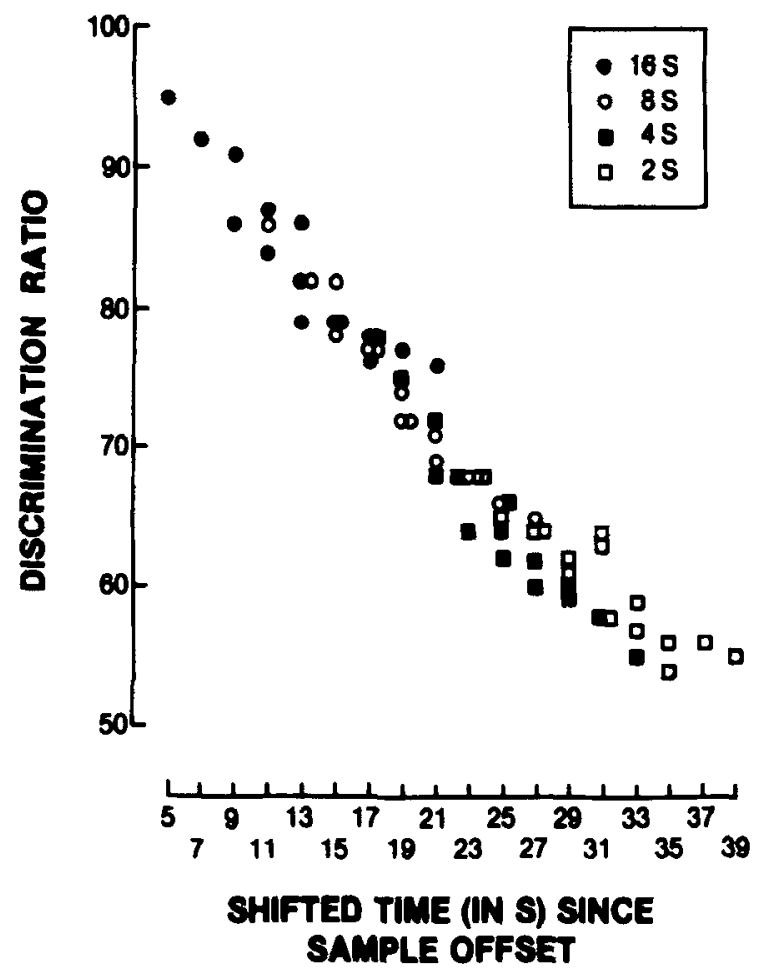

Figure 6. Mean discrimination ratios over shifted time since sample offset with sample duration as the parameter. The 8-, 4, and 2-sec sample duration functions have been shifted to the right (see text). 
Table 1

Mean Response Rates (Pecks/Second) to Matching (M) and Nonmatching $(\mathrm{N})$ Test Stimuli

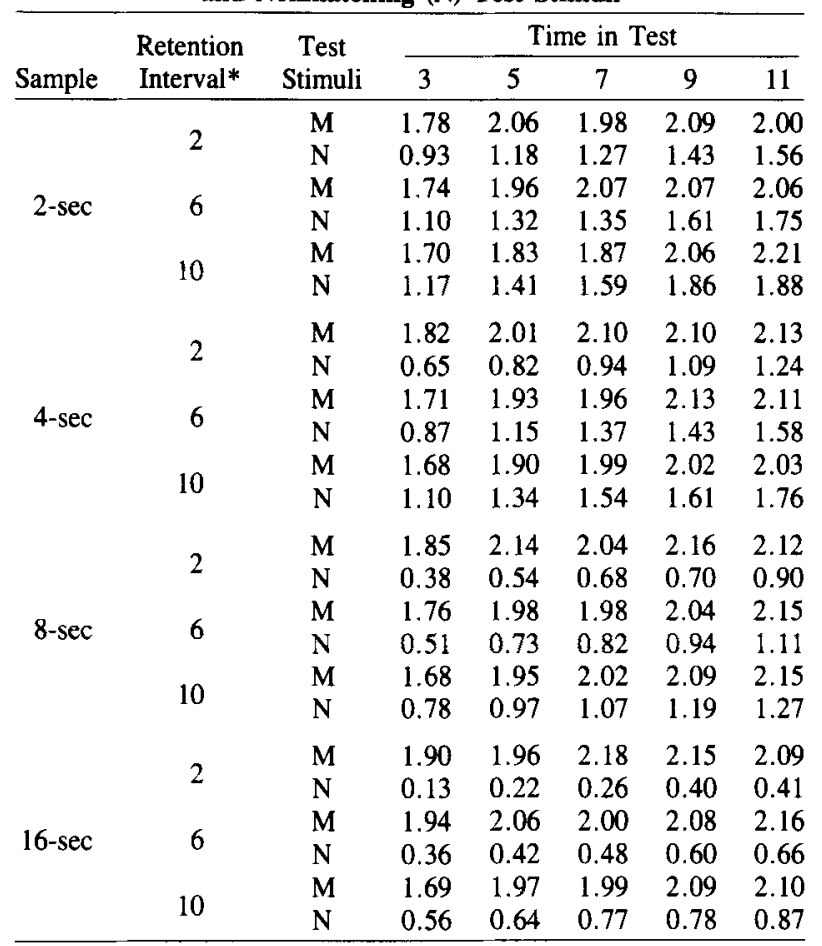

*Retention interval in seconds.

test retention interval (Nelson \& Wasserman, 1978; Roberts \& Grant, 1976). These outcomes correspond, respectively, with the growth and the decay of a hypothetical memory trace, whose strength is said to be proportional to discriminative DMTS performance (Roberts \& Grant, 1976).

Our results showed that DMTS performance was a negatively accelerated function of sample duration (Figure 1). This finding suggests that trace growth is a nonlinear increasing function of sample exposure. Our results also showed that DMTS performance fell linearly as the retention interval was lengthened (Figure 2). This finding, coupled with the fact that there was no reliable interaction between sample duration and retention interval, suggests that decay of the memory trace proceeds as a simple linear function of time since offset of the sample stimulus. This set of results, obtained using the go/no-go DMTS method, thus closely corresponds with that obtained under the choice DMTS procedure (Roberts \& Grant, 1976).

Other outcomes of the present study are novel and extend our knowledge of DMTS behavior. First, by carefully monitoring the time course of discriminative test responding, we found that DMTS performance decreased as a function of the passage of time in the test (Figure 3). Second, we found that discriminative DMTS performance fell at virtually the same rate whether the retention interval was lengthened or time passed in the test. We note three results relevant to the second conclusion:

(1) When DRs for each sample duration were plotted as a function of the time since offset of the sample stimu- lus (Figure 5), the data points approximated straight lines, even though DRs at the same time since sample offset involved different combinations of retention intervals and test times. For example, at 12 to $14 \mathrm{sec}$ since sample offset, one data point in each of the four graphs in Figure 5 came from a 2 -sec retention interval and recorded behavior from 10 to $12 \mathrm{sec}$ of the test; another came from a 6-sec retention interval and recorded behavior from 6 to $8 \mathrm{sec}$ of the test; and the remaining point came from a 10 -sec retention interval and recorded behavior from 2 to $4 \mathrm{sec}$ of the test. The resulting generally linear functions suggest that how long it has been since offset of the sample stimulus is the major determinant of forgetting in this situation-not how that time was spent (in the retention interval or in the test period).

(2) When the four graphs in Figure 5 were replotted through lateral displacement so that the initial points of the 8-, 4-, and 2-sec functions coincided with the fourth point of the next longer sample duration, the composite DR function (Figure 6) was also a generally linear relation. Here, shorter sample durations were essentially: equivalent to longer times since sample offset; adding $6 \mathrm{sec}$ to the time since sample offset for successive decreases in sample duration (from 16 to $8 \mathrm{sec}$; from 8 to $4 \mathrm{sec}$; and from 4 to $2 \mathrm{sec}$ ) had little effect on the overall shape of the memory gradient.

(3) DR decreased similarly when either the retention interval (a decrement of 10.2; Figure 2) or time in the test (a decrement of 9.4; Figure 3) was increased by $8 \mathrm{sec}$.

These new results also support trace theory. Specifically, they support a multiple comparison version of trace theory, which holds that, for the duration of the test, the pigeon bases its discriminative responding upon repeated comparisons of the prevailing test stimulus with a fading memory trace of the prior sample stimulus. The growth function of the memory trace appears to be nonlinear. The decay function appears to be mainly linear; however, the reliable retention interval $\times$ test time interaction (Figure 4) and the shape of the composite delay gradient (Figure 6) suggest some slight nonlinearity. In either case, the rate of trace decay seems to be the same over the retention interval and over the passage of time in the test.

Although these results are consistent with a multiple comparison version of trace theory, several cautionary points are noteworthy. First, the hypothesized memory trace is an intervening variable (Roberts \& Grant, 1976). We never measure its strength directly; we measure only its behavioral effects. Thus, many quantitative questions-such as whether trace growth and decay are linear or nonlinear functions of time-are extremely difficult ones to answer, because there need be no one-to-one correspondence between trace strength and discrimination ratio (DR). Furthermore, different measures of discrimination performance may be more or less linear functions of time. Figure 6 showed the composite delay gradient that resulted from one index of discrimination; its shape was slightly exponential. Figure 7 shows the composite delay gradient that results from another discrimination 
index: $\mathrm{DR}=[1-.5$ (rate of response on nonmatching trials) $/$ (rate of response on matching trials) $] \times 100-$ (cf. Wasserman, 1976). The latter gradient displays no hint of being exponential; a simple linear equation here accounts for $96.32 \%$ of the variance. But, if different measures of discrimination performance themselves define differently shaped delay gradients, how can we ever decide whether the memory trace that they purportedly reflect is a linear or nonlinear function of time?

Second, trace theory may not be the only theoretical model capable of explaining the obtained results. Trace theory is retrospective: it says that cues to current response decisions come from residues of past stimulation (in combination with the prevailing test stimuli). Other accounts are prospective: they claim that current response decisions may be anticipated by animal subjects. Such anticipatory or expectational accounts do a good job in accounting for other features of DMTS performance in which trace theory fares poorly (Grant, 1981; Honig, 1978; Honig \& Wasserman, 1981; Peterson, Wheeler, \& Armstrong, 1978; Peterson, Wheeler, \& Trapold, 1980).

How could prospection be applied to performance in the go/no-go DMTS paradigm? Honig (1978) and Grant (1981) proposed that presentation of the sample stimulus elicits an instructional code, which contains information about "what to do" rather than about "what happened." In the present task, such codes might be "peck orange test stimulus" or "peck green test stimulus." If it is assumed that increased exposure to the sample stimulus increases the probability of activating the instruction, then

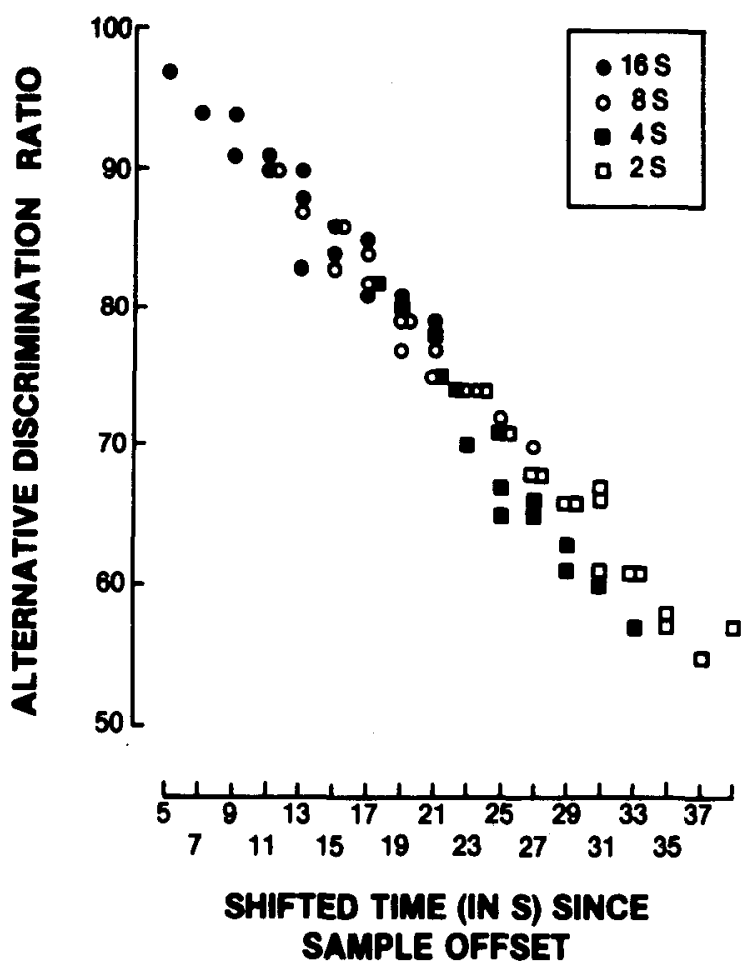

Figure 7. Alternative discrimination ratios over shifted time since sample offset with sample duration as the parameter (see text). we can understand the sample duration-DR relationship. And if it is assumed that increases in the retention interval increase the probability of the instruction returning to an inactive state, then we can understand the retention interval-DR relationship. However, there is no strong reason to assume that discriminative responding should decrease during the test period, or that the rate of the decrement should be the same as that during the retention interval. Indeed, the research of Honig and Wasserman (1981) would suggest that, since the pigeon can determine at the beginning of the test stimulus whether food or blackout will be the trial outcome, any instruction "to peck" or "not to peck" should be well retained until the end of the test period; little or no loss in discriminative performance would then be expected as a function of the passage of time in the test. Certainly, any loss should be more gradual than that occurring over the retention interval, during which more complex information must be retained.

A third concern involves the exact response-rate changes that were occasioned by manipulation of the three independent variables. Increases in sample duration decreased test response rate on nonmatching trials, but did not affect test response rate on matching trials; increases in the retention interval increased test response rate on nonmatching trials, but decreased test response rate on matching trials; and test response rate rose on both types of trials as time passed during the test stimulus, but more so on nonmatching trials. Are all three patterns of response-rate changes due (at least in part) to the same process, such as the fading of an internal memory trace? Or is each pattern the result of different mechanisms? Here, too, a ready answer is not obvious.

We have entertained the simple assumption that the concept of the memory trace is a good place to begin our analysis of DMTS performance. This assumption not only inspired the present investigation, but also made it possible for us to combine the effects of three independent variables with one intervening variable (also see Church, 1978). The nice composite decay function in Figure 6 could, of course, be a happy accident. Only further research will tell.

And what of the increases in response rate seen on both matching and nonmatching trials as time passed in the test (Table 1)? Perhaps these absolute increases were due to the rise in the momentary probability of reinforcement from $4 \mathrm{sec}(.17)$ to $8 \mathrm{sec}(.33)$ to $12 \mathrm{sec}(.50)$ into the test. Nevertheless, the involvement of this temporal discrimination may not seriously color our view of the memory process when assessed by a relative measure of performance, such as the present DR. Again, only future work can shed light on this issue.

In any event, even though no general model of delayed discrimination performance is in the immediate offing, the continued exploration of different accounts-such as trace theory-has merit, at least insofar as such research helps to define the limits of their applicability. Knowing when various theories succeed and when they fail may better enable us to construct broader and more accurate models of animal memory. 


\section{REFERENCES}

Blough, D. S. (1959). Delayed matching in the pigeon. Journal of the Experimental Analysis of Behavior, 2, 151-160.

Church, R. M. (1978). The internal clock. In S. H. Hulse, H. Fowler, \& W. K. Honig (Eds.), Cognitive processes in animal behavior. Hillsdale, NJ: Erlbaum.

Ferster, C. B., \& SKINNer, B. F. (1957). Schedules of reinforcement. New York: Appleton-Century-Crofts.

GraNT, D. S. (1976). Effects of sample presentation time on long-delay matching in the pigeon. Learning and Motivation, 7, 580-590.

Grant, D. S. (1981). Short-term memory in the pigeon. In N. E. Spear \& R. R. Miller (Eds.), Information processing in animals: Memory mechanisms. Hillsdale, NJ: Erlbaum.

GUTTENBERGER, V. T. (1983). Effects of sample duration, retention interval, and passage of time in the test on pigeons' matching-to-sample performance. Unpublished master's thesis, University of Iowa.

HonIG, W. K. (1978). Studies of working memory in the pigeon. In S. H. Hulse, H. Fowler, \& W. K. Honig (Eds.), Cognitive processes in animal behavior. Hillsdale, NJ: Erlbaum.

Honig, W. K., \& Wasserman, E. A. (1981). Performance of pigeons on delayed simple and conditional discriminations under equivalent training procedures. Learning and Motivation, 12, 149-170.

KonORSKI, J. A. (1959). A new method of physiological investigation of recent memory in animals. Bulletin de l'Academie Polonaise des Sciences Série des Sciences Biologiques, 7, 115-117.

Nelson, K. R., \& Wasserman, E. A. (1978). Temporal factors influencing the pigeon's successive matching-to-sample performance: Sample duration, intertrial interval, and retention interval. Journal of the Experimental Analysis of Behavior, 30, 153-162.
Peterson, G. B., Wheeler, R. L., \& Armstrong, G. D. (1978). Expectancies as mediators in the differential-reward conditional discrimination performance of pigeons. Animal Leaming \& Behavior, 6, 279-285.

Peterson, G. B., Wheeler, R. L., \& Trapold, M. A. (1980). Enhancement of pigeons' conditional discrimination performance by expectancies of reinforcement and nonreinforcement. Animal Learning \& Behavior, 8, 22-30.

RoBERTS, W. A. (1972). Short-term memory in the pigeon: Effects of repetition and spacing. Joumal of Experimental Psychology, 94, 74-83.

RoBERTS, W. A., \& GRANT, D. S. (1976). Studies of short-term memory in the pigeon using the delayed matching-to-sample procedure. In D. L. Medin, W. A. Roberts, \& R. T. Davis (Eds.), Processes of animal memory. Hillsdale, NJ: Erlbaum.

Rortblat, H. L. (1980). Codes and coding processes in pigeon shortterm memory. Animal Learning \& Behavior, 8, 341-351.

SNapper, A. G., Stephens, K. R., \& LeE, D. M. (1974). The SKED software system. Kalamazoo, MI: The SKED Users Group, Psychology Department, Western Michigan University.

W ASSERMAN, E. A. (1976). Successive matching-to-sample in the pigeon: Variations on a theme by Konorski. Behavior Research Methods \& Instrumentation, 8, 278-282.

WILKIE, D. M., \& SPETCH, M. L. (1981). Pigeons' delayed matching to sample errors are not always due to forgetting. Behaviour Analysis Letters, 1, 317-323.

(Manuscript received October 15, 1984; revision accepted for publication April 8, 1985.) 